\title{
UNIVERSALISMO DE DIREITOS E ASSIMILACIONISMO / UNIVERSALISM OF RIGHTS AND ASSIMILATIONISM
}

\author{
Juan Cianciardo ${ }^{1}$
}

\begin{abstract}
Resumo
O presente artigo procura estudar um problema que pode ser sintetizado no desafio de conciliar o universalismo dos direitos com o direito à identidade cultural.

Trata-se de um desafio que foi definido historicamente a partir de duas perspectivas extremas, que tendem a deslocar um dos termos do problema - o universalismo ou a identidade cultural -, juntamente com tentativas harmonizadoras intermediárias. Aqui nesse artigo nos concentraremos no estudo de uma das perspectivas aludidas: concretamente, na resposta assimilacionista.
\end{abstract}

Palavras-chave: Universalismo de direitos. Direito à identidade cultural. Resposta assimilacionista..

\begin{abstract}
This paper tries to study a problem that can be synthesized in defiance of reconciling universalism of rights with the right to cultural identity.

This is a challenge that has been defined historically from two extreme perspectives, which tend to displace one of the terms of the problem - the universalism or cultural identity - along with intermediate harmonizing attempts. Here in this article we will focus on the study one of the perspectives alluded to: namely, the assimilationist response.
\end{abstract}

Keywords: Universalism rights. Right to cultural identity. Assimilationist response..

1. A imigração, o multiculturalismo e seus problemas

Como fenômeno sociológico, a imigração e seus problemas são tão antigos como a história do homem. Contudo, nunca, como na última parte do século passado e no início deste, os fluxos migratórios foram tão intensos e extensos, com a carga de transformação que isso leva consigo, tanto para o país que assiste à partida de seus nacionais como para o que os recebe.

\footnotetext{
${ }^{1}$ Pesquisador do CONICET (Consejo Nacional de Investigaciones Científicas y Técnicas de la Argentina). Professor Titular de Filosofia do Direito na Universidade Austral, de Buenos Aires, onde, além disso, desempenha-se como Diretor de sua Faculdade de Direito. Tradução do espanhol por Frederico Bonaldo, Professor do CEPED-UERJ, Mestre em Direito pela UERJ e Doutorando em Direito na Universidad Austral (Buenos Aires, Argentina).
} 
A globalização impulsionou a imigração e, com ela, não só dificuldades de emprego e de distribuição como também o multiculturalismo, a convivência no seio de uma mesma sociedade de grupos sociais com culturas diferentes, com uma gama nova de problemas ${ }^{2}$.

Isto representou um desafio para o Direito de extensões vastas e calado profundo, com uma gama de matizes que não é possível enumerar num trabalho com estas características.

Como é sabido, um dos temas centrais da teoria geral dos direitos humanos é o da característica universalidade dos direitos, uma das propriedades definidoras que permitem diferenciá-los dos direitos simpliciter ${ }^{3}$. Se os direitos humanos significaram algo foi a sua validade universal, sincrônica e diacrônica. Pois bem, como se pode constatar quase de modo diário, a imigração multicultural representou banco de provas do universalismo. Com efeito, é evidente a existência de uma tensão entre os que pretendem fazer valer os direitos humanos no seio de todas as culturas que formam parte de um Estado, e, inclusive, pretendem idêntico fim para além de um Estado concreto, com base nesse caráter universal, e os que sustentam que, pelo contrário, os direitos humanos não valem para além da cultura ocidental que os viu nascer e lhes outorgou carta de cidadania.

Assim vistas as coisas, o problema central que se apresenta no contexto anterior pode ser sintetizado no desafio de conciliar o universalismo dos direitos com o direito à identidade cultural. Trata-se de um desafio que foi encarado historicamente a partir de duas perspectivas extremas, que tendem a deslocar um dos termos do problema - o universalismo ou a identidade cultural -, juntamente com tentativas harmonizadoras intermediárias ${ }^{4}$. Aqui nos concentraremos numa das perspectivas aludidas: concretamente, na resposta assimilacionista. Ficará para trabalhos posteriores o exame da resposta multiculturalista e das tentativas de harmonização.

\footnotetext{
${ }^{2}$ Cf., entre muitíssimos outros, ViOLA, F. "La società multiculturale como società politica" In: Studi Emigrazione / Migration Studies XLI, n. 153 (2004), pp. 83-90. Cabe esclarecer que, como menciona o própio Viola, o fenômeno do multiculturalismo não depende exclusivamente da imigração: faz-se também presente naqueles casos em que uma cultura indígena local aspira a conservar a sua identidade de origem frente ao fenômeno do colonialismo (cf. idem, pp. 84-85). Cf., igualmente, ViolA, F., "Democrazia culturale e democrazia delle culture" In: Studi Emigrazione / Migration Studies XXXVIII, n. 144 (2001), pp. 845-854. Sobre alguns dos fatores contemporâneos que têm incidido no multiculturalismo, cf. ANDORNO, R., "Universalismo de derechos humanos y derecho natural", Persona y Derecho 38 (1998*), pp. 35-49, pp. 35-36. ${ }^{3}$ Cf., por exemplo, entre muitos outros, AA.VV. Pluralità delle culture e universalità dei diritti, Studi racoliti da Francesco D’Agostino. Torino : Giappichelli, 1996, passim.

${ }^{4}$ Sobre a importância de procurar uma visão harmônica dos direitos, cf. CIANCIARDO, J. El ejercicio regular de los derechos. Análisis y crítica del conflictivismo. Buenos Aires : Ad-hoc, 2007, passim.
} 


\section{O assimilacionismo}

Na opinião de Encarnación Fernández «[o] assimilacionismo consiste na primazia, no predomínio ou na imposição de uma cultura sobre as demais. Isto pode acontecer no interior de uma comunidade política particular e também no âmbito das relações internacionais. Neste último, por obra, primeiro, do colonialismo, e, depois, do neo-colonialismo e da globalização» ${ }^{5}$. A posição assimilacionista registra diversos níveis, que vão desde um assimilacionismo extremo, que parte da superioridade da cultura ocidental para concluir, então, na obrigação ética dos Estados ocidentais de impor pela força os seus valores culturais, até a assunção, como uma conseqüência inevitável da atual economia de mercado globalizado, passando por versões intermediárias, que o entendem como «necessário para assegurar a coesão e a paz social» ${ }^{6}$.

\footnotetext{
${ }^{5}$ FERNÁNDEZ, E. “¿Cómo conjugar universalidad de los derechos y diversidad cultural?” In: Persona y Derecho $49^{* *}$ (2003), pp. 393-444, p. 410.

${ }^{6}$ Idem, p.

411.

${ }_{7}$ Cf. a respeito, RIVAS, P. “Laicismo francés y sociedad liberal” In: Revista del Poder Judicial 73 (2004), pp. 217-232, passim. Cf., igualmente, do mesmo autor, Las ironías de la sociedad liberal. México : Instituto de Investigaciones Jurídicas de la Universidad Nacional Autónoma de México, 2004; JIMÉNEZ-AYBAR, I. "El Islam en una Europa multicultural" In: Aequalitas 10-11 (2002), pp. 20 y ss. Sobre outras decisões do Conselho de Estado francês vinculadas com o nosso tema, cf. BRIONES, I. "Libertad religiosa y de conciencia en la enseñanza laica" In: Humana Iura 5 (1995), pp. 93 ss.

Com relação ao tema do véu islâmico, na Resolução do Parlamento Europeu sobre as mulheres e o fundamentalismo [2000/2174 (INI)], disse-se: «S. Considerando que as mulheres devem ter a possibilidade e a liberdade de escolher ou não uma confissão religiosa e de utilizar os símbolos religiosos que a expressam, se elas mesmas desejarem colocar em evidência a sua identidade. T. Considerando que a identidade da mulher há de poder ser pessoal e individual, diferenciada de religiões, tradições e culturas; que estereótipos, vestido, valores, modelos de vida e hábitos de comportamento devem ser uma questão de livre escolha pessoal». Assinala E. Fernández que: «certamente, o véu pode ser considerado como um símbolo de sujeição das mulheres. Nesse sentido, não há que esquecer-se a longa luta das mulheres muçulmanas pela sua supressão. No entanto, o uso do véu pode ser vivido pelas mulheres como um símbolo - em absoluto opressivo - de identidade cultural e religiosa. Tudo parece indicar que esta segunda atitude está muito estendida na atualidade entre as mulheres muçulmanas. Entendo que, em relação aos que assim o experimentam, o uso do véu é uma manifestação do direito à proteção da própria identidade cultural» (FERNÁNDEZ, E. “¿Cómo conjugar universalidad de los derechos y diversidad cultural?", art. cit., p. 436). 8

Cf. FERNÁNDEZ, E. «¿Cómo conjugar universalidad de los derechos y diversidad cultural?», art. cit., pp. 410411. Ali se assinala: «o assimilacionismo pode-se impor por via autoritária e coativa. Os poderes autoritários pretendem unificar culturalmente a sociedade em nome da razão, da nação, da raça ou, inclusive, da religião. Mas também existem outros modos mais suaves e sutis de homogeneização cultural, como a levada a cabo em nome do progresso e das luzes e da racionalidade da lei. Assim, o modelo nacional-democrático teria o mérito de ter dado cabida ao pluralismo político, porém, frequentemente, foi acompanhado de uma rejeição e de uma destruição da diversidade cultural. Os casos da França e dos Estados Unidos são paradigmáticos. Ao
} 
De acordo com esses níveis ou graus de assimilacionismo, também variam as formas de sua imposição. $\mathrm{O}$ assimilacionismo extremo não vacilará em recorrer à violência, com vistas a estender-se e a impor-se, inclusive à violência revestida com a roupagem formal de uma norma. Um exemplo disto pode-se encontrar na proibição do uso do foulard islamique na França ${ }^{7}$. No outro extremo, o assimilacionismo impõe-se quase de modo não deliberado, através do cinema, da televisão e, em geral, da promoção do estilo de vida estadunidense que os mass media levam a cabo ${ }^{8}$.

Um expoente do assimilacionismo, com relação específica à convivência entre a Europa e os muçulmanos, é Oriana Fallaci ${ }^{9}$. Para a jornalista italiana, o Islã não é sequer uma civilização. Escreveu a respeito: «[c]ontinua o discurso sobre o diálogo entre as duas civilizações. E que me trague a terra se me perguntam qual é a outra civilização, o que há de civilizado numa civilização que não conhece sequer a palavra liberdade. Que por liberdade entende a "emancipação da escravidão". Que cunhou a palavra liberdade no final do século XIX para poder assinar um tratado comercial. Que na democracia vê Satanás e a combate com explosivos, cortando cabeças» ${ }^{10}$.

Perante esse estado de situação, cristianismo e islamismo seriam inconciliáveis. Fallaci queixa-se amargamente da posição da Igreja Católica, que sublinha o «patrimônio espiritual comum transmitido a nós pelas três grandes religiões monoteístas»: a cristã, a judaica, a islâmica. Pergunta-se: «mas que patrimônio comum? Alá é um deus patrão, um deus tirano. Um deus que vê nos homens os seus súditos e até mesmo os seus escravos. Um deus que, no lugar de amor, prega o ódio, que através do Corão chama cães infiéis os que crêem em outro deus e ordena que sejam castigados. Subjugá-los, matá-los» ${ }^{7}$.

\section{Algumas críticas ao assimilacionismo}

mesmo tempo em que se desenvolviam o republicanismo, a democracia, as liberdades públicas, fazia-se um grande esforço por criar uma nação culturalmente homogênea».

9

Além dos artigos que se citarão depois, cf. FALLACI, O. Oriana Fallaci intervista sé stessa. L'Apocalisse. Milano : Libri, 2005. Cita-se a partir da versão em espanhol: FALLACI, O. Oriana Fallaci se entrevista a sí misma. El Apocalipsis, trad. de J. M. Vidal. Buenos Aires : Ateneo, 2005, passim.

10

FALLACI, O. "El inútil diálogo que el Islam rechaza desde hace 1400 años”, em La Nación, Buenos Aires, 19 de julio de 2005 , p. 3.

${ }^{7}$ Ibidem.

Revista Quaestio Iuris, vol.04, nº1. ISSN 1516-0351 p.513-521 516 


\subsection{Assimilacionismo e igualdade}

O assimilacionismo confunde diferença com barbárie, e não detecta no fato da diversidade cultural a porta de ingresso a um mútuo enriquecimento. Trata-se de uma consequiência a mais do disjuntivismo que acomete a cultura contemporânea desde a Modernidade. Segundo Ballesteros ${ }^{8}$, a partir de então desencadearam-se três processos de desvalorização: o oral em favor do visual, o qualitativo em favor do quantitativo, o analógico em favor do disjuntivo ${ }^{9}$. A cada um deles corresponde uma figura destacada, respectivamente: Leonardo da Vinci, Galileu e Descartes.

Descartes (1596-1650) assume a sistematização e a explicação de toda a evolução aludida ${ }^{10}$. Com ele começa o primado do disjuntivo sobre o analógico. No pensamento cartesiano, o homem fica dividido em duas partes incomunicadas, tem um corpo, res extensa, submetido ao espaço e à geometria, e é res cogitans, em razão do que está fora do espaço e do tempo. Como ele mesmo explica: «... a partir do fato de que sei que existo e de que, enquanto isso, não advirto que à minha natureza ou à minha essência pertence absolutamente qualquer outra coisa a mais que tão somente isto: que eu sou uma coisa pensante, retamente concluo que a minha essência consiste unicamente nisto: que eu sou uma coisa pensante. $\mathrm{E}$ ainda que talvez (ou, melhor, como depois direi, certamente) eu tenha um corpo que está muito estreitamente unido a mim, no entanto, posto que, por um lado, tenho a idéia clara e distinta de mim mesmo, enquanto sou só uma coisa pensante, não extensa, não pensante, certo é que eu sou realmente distinto de meu corpo, e que posso existir sem ele» ${ }^{11}$.

Para esta auto-compreensão, «a realidade mais imediata e entranhável, a unidade psicossomática da pessoa humana, resulta uma aporia insuperável (...) [como conseqüência] (...) do pensar disjuntivo e exato, que nega a analogia» ${ }^{12}$. E, daí em adiante, toda a realidade

\footnotetext{
${ }^{8}$ Cf. BAllesteros, J. Postmodernidad: decadencia o resistência. Madrid : Tecnos, 1989, pp. 17-24.

${ }^{9}$ Cf. Cianciardo, J. El ejercicio regular de los derechos..., op. cit., pp. 140-146.

${ }^{10}$ Cf. B Allesteros, J. Postmodernidad: decadencia o resistencia, op. cit., p. 22.

${ }^{11}$ DESCARTES, R. Meditationes de prima philosophia, In: Ouvres philosophiques. Paris : Garnier, 1973, t. II, pp. 177 et seq. Cita-se a partir da edição em castelhano, Meditaciones metafísicas y otros textos, trad. y notas de E. López y M. Graña. Madrid : Gredos, 1987, «Sexta Meditación: De la existencia de las cosas materiales y de la distinción real entre el alma y el cuerpo», pp. 65-82, p. 71.

${ }^{12}$ BALlesteros, J. Postmodernidad: decadencia o resistencia, op. cit., p. 22. Sobre a analogia e o disjuntivismo, cf., igualmente, LlANO, A. La nueva sensibilidad. Madrid : Espasa-Calpe S.A., 1988, pp.
} 
seria abordada em termos de univocidade, de identidade-oposição e não de diferençacomplementaridade ${ }^{13}$. O «isto ou aquilo» é a chave da aproximação moderna às coisas, e fonte inevitável das tão numerosas como falsas disjuntivas que afetaram ou afetam a nossa época: comunismo-liberalismo, indivíduo-sociedade, hedonismo-puritanismo, deverfelicidade, liberdade-igualdade, ecologia-progresso etc. Como se verá ao se examinar o conceito moderno de Direito, muitos problemas jurídicos atuais só se compreendem a partir desta perspectiva (e, ademais, só a partir dela são apresentados). Singularmente, merece destacar-se a oposição maniqueísta entre liberdade jurídica e igualdade jurídica ${ }^{14}$.

$\mathrm{O}$ dito precedentemente explica que « $[\mathrm{e}] \mathrm{m}$ todas as hipóteses, o resultado do assimilacionismo é a eliminação das diferenças. E não só isto. $\mathrm{O}$ assimilacionismo dá lugar ao que Touraine denomina "sociedade integrada e desigual", que exclui a diferença, mas também a igualdade, posto que favorece os que se encontram mais próximos do modelo social e cultural central» ${ }^{15}$.

\subsection{Um diálogo frustrado}

As consequiências de uma proposição desse tipo começam a serem percebidas com nitidez: é preciso negar-se a todo diálogo - Fallaci critica, com a sua advertência nesta direção, tanto João Paulo II como Bento XVI - e resulta inevitável um enfrentamento violento que dará lugar ao predomínio do mais forte. Tal enfrentamento é exigido, segundo a jornalista italiana, pelo «princípio de autodefesa, de legítima defesa» ${ }^{16}$. Para esta visão, uma atitude diferente só se explicaria pela debilidade espiritual do Ocidente. Com palavras da própria Fallaci: «a decadência dos ocidentais se identifica com a sua ilusão de poder tratar amigavelmente o inimigo, inclusive temendo-o. Um medo que os induz a albergar o inimigo docilmente, a tentar conquistar a sua simpatia, a esperar que se deixe absorver (...), o hábito

\footnotetext{
212233; e KAUFMANN, A. Analogía y naturaleza de la cosa: hacia una teoría de la comprensión jurídica. Santiago de Chile : Editorial Jurídica de Chile, 1976, passim.

${ }^{13}$ Cf. B Allesteros, J. Postmodernidad: decadencia o resistencia, op. cit., p. 23.

${ }^{14} \mathrm{Cf}$., a respeito, CIANCIARDO, J. El ejercicio regular de los derechos..., op. cit., pp. 153-159 e 165-182.

${ }^{15}$ FERNÁNDEZ, E. “¿Cómo conjugar universalidad de los derechos y diversidad cultural?”, art. cit., pp. 410411. A citação de Touraine em TourAINE, A. Pourrons-nous vivre ensamble? Égaux et différents. Paris : Fayard, 1997, pp. 197-201 e TourAine, A. Igualdad y diversidad. Las nuevas tareas de la democracia. $2^{a}$ ed., trad. de R. González. México : Fondo de Cultura Económica, 2000, pp. 77-79 e 82.

${ }^{16}$ Ibidem.
} 
gera resignação. A resignação gera apatia. A apatia gera inércia. A inércia gera indiferença e impede o juízo moral. A indiferença sufoca o instinto de autodefesa» ${ }^{17}$.

A posição da Igreja Católica sobre este tema foi expressa com nitidez na Declaração do Concílio Vaticano II «Nostra aetate. Sobre as relações da Igreja com as religiões não cristãs», de 28 de outubro de 1965. Disse-se ali que: «A Igreja católica não rejeita nada do que nessas religiões há de santo e verdadeiro. Considera, com sincero respeito, os modos de agir e de viver, os preceitos e doutrinas que, por mais que muito discrepem do que ela professa e ensina, não poucas vezes refletem uma centelha daquela Verdade que ilumina todos os homens. Anuncia e tem a obrigação de anunciar constantemente Cristo, que é "o Caminho, a Verdade e a Vida" (Jo 14, 6), em quem os homens encontram a plenitude da vida religiosa e em quem Deus reconciliou consigo todas as coisas. Por conseguinte, exorta os seus filhos a que, com prudência e caridade, mediante o diálogo e a colaboração com os adeptos de outras religiões, dando testemunho de fé e de vida cristã, reconheçam, guardem e promovam aqueles bens espirituais e morais, bem como os valores sócio-culturais que neles existem» (N. 2). Com relação ao Islã, o Concílio precisou o seguinte: «A Igreja também olha com apreço os muçulmanos que adoram o único Deus, vivente e subsistente, misericordioso e todo-poderoso, Criador do céu e da terra, que falou aos homens, a cujos ocultos desígnios procuram submeter-se com toda a alma como a Deus se submeteu Abraão, a quem a fé islâmica olha com complacência. Veneram Jesus como profeta, embora não o reconheçam como Deus; honram Maria, sua Mãe virginal, e, às vezes, também a invocam devotamente. Esperam, além disso, o dia do juízo, quando Deus remunerará todos os homens ressuscitados. Por isso, apreciam, ademais, o dia do juízo, quando Deus remunerará todos os homens ressuscitados. Portanto, apreciam a vida moral e honram a Deus, sobretudo com a oração, com as esmolas e com o jejum. Se, no transcurso dos séculos, surgiram não poucas desavenças e inimizades entre cristãos e muçulmanos, o Sagrado Concílio exorta a todos para que, esquecendo o passado, procurem e promovam, unidos, a justiça social, os bens morais, a paz e a liberdade para todos os homens» (N. 3).

A partir desta perspectiva, o diálogo intercultural e, mais especificamente, o diálogo do Ocidente com o Islã, são considerados como desejáveis e enriquecedores ${ }^{22}$. Ainda que o

\footnotetext{
${ }^{17}$ FALLACI, O. “Italia y el arte, las próximas víctimas”, em La Nación, Buenos Aires, 20 de julio de 2005, p. 3.
} 
reconhecimento mútuo que todo diálogo implica se projete numa série de condições específicas, sem cujo respeito não resulta possível dialogar ${ }^{23}$.

\subsection{Assimilacionismo, direitos de segunda geração e imposição}

As posturas assimilacionistas - que, dentro dos Estados, pretendem impor aos grupos sociais os direitos de primeira geração em geral, em nome do universalismo desses direitos costumam ser resistentes à hora de reconhecer os direitos de segunda geração, em particular o direito ao trabalho. Dito de outro modo, o assimilacionismo impõe os direitos de primeira geração, mas nega os de segunda. O seu universalismo, por isso, é pela metade. Trata-se de universalizar uma visão enviesada do ser humano: a visão antropológica do liberalismo ocidental. Para esta posição, o homem é, sobretudo, um eleitor ${ }^{24}$. Garantido o voto, pareceria que se garante tudo o que vale a pena garantir. Inclusive o peso do reconhecimento de outros direitos diferentes dos políticos - a liberdade de contratação, a liberdade de expressão... - dependerá da sua incidência sobre os direitos políticos.

O que aparece encoberto ou não explicitamente dito é que por detrás da imposição dos direitos de primeira geração se esconde a negativa ao reconhecimento de outros direitos que fazem efetivamente possível o seu exercício. Deste modo, este reconhecimento ambivalente e incompleto acaba reduzindo inclusive aquilo que se pretende reconhecer a mera declamação, da qual não se extraem conseqüências jurídicas de relevo.

Por outro lado, o reconhecimento more assimilacionista dos direitos de primeira geração vai unido à imposição de pautas culturais ocidentais específicas, para além desses direito, atentando-se, deste modo, contra uma das dimensões básicas da pessoa, posto que, por esta via, nega-se o respeito da identidade cultural e, mais amplamente, a dimensão social da existência humana. Não existe o direito a uma identidade cultural, mas uma cultura que impõe o seu poder sobre as outras.

Nega-se, por esta via, a possibilidade de um diálogo intercultural em chave de direitos, baseados sobre a igual dignidade e natureza de todos os seres humanos. Paradoxalmente, o assimilacionismo termina em particularismo ascendente, embora poderoso, auto-suficiente, e que se auto-proclama superior. Assim, «despojada do traço da 
racionalidade, a noção de direitos humanos se desvirtua, perde o seu sentido e o seu significado próprios, o seu poder emancipador e protetor» ${ }^{18}$ : dissolve-se, numa palavra.

${ }^{18}$ FERNÁNDEZ, E. “¿Cómo conjugar universalidad de los derechos y diversidad cultural?”, art. cit., p. 409. No
mesmo sentido, SEOANE, J. A. "La universalidad de los derechos y sus desafíos. (Los "derechos especiales” de
las minorías)” In: Persona y Derecho $38\left(1998^{*}\right)$, pp. 187-226, pp. 187-190.
${ }^{22}$ Cf., em relação a este ponto, BENTO XVI. "Fé, razão e universidade. Recordações e reflexões”, Discurso na
Universidade de $\quad$ Ratisbona, $12 \quad$ de $\quad$ setembro de 2006, em http://www.vatican.va/holy father/benedict_xvi/speeches/2006/september/documents/hf_benxvi_spe 2006091 2 university-regensburg sp.html, acesso em 28 de fevereiro de 2007. O Papa atual fala ali da «urgente necessidade» de um «autêntico diálogo nas culturas e nas religiões».

23 Cf. ibidem. Ali se afirma, por exemplo, que «a difusão da fé mediante a violência é algo insensato», e que «não atuar segundo a razão é contrário à natureza de Deus».

24 Como assinalou com acuidade A. Cruz Prados, ao criticar o anti-perfeccionismo liberal, o Estado liberal «constitui um ethos liberal, no qual o homem adquire uma identidade peculiar, cuja plenitude lhe propõe exigências práticas, e, frente às quais — tal plenitude e tais exigências —, o Estado não é, de modo algum, indiferente, mas, sim, claramente perfeccionista. A diferença se encontra só no tipo de identidade que proporciona ao indivíduo, que não é senão a de puro eleitor. Trata-se de uma identidade que tem por substância a nossa capacidade de escolher autonomamente, o que exige viver os conteúdos da nossa existência como puras opções autônomas e evitar, ao mesmo tempo, que qualquer opção adquira o caráter de constitutiva para o sujeito, pois, do contrário, passaria a mediar as eleições futuras, perdendo estas autonomia, isto é, ficando o indivíduo rebaixado em sua condição de puro eleitor. Toda eleição há de ser, efetivamente, trivil. O Estado liberal está ordenado, realmente, para fazer do cidadão um bom liberal. Não importa o que o indivíduo escolha; só lhe exige que o escolha liberalmente» (CRUZ PRADOS, A. Ethos y polis. Bases para una reconstrucción de la filosofía política. Pamplona : Eunsa, 1999, p. 25). 